\title{
Capture of Uranium Particles by Filtration: Effects of Filter Material and Air Humidity
}

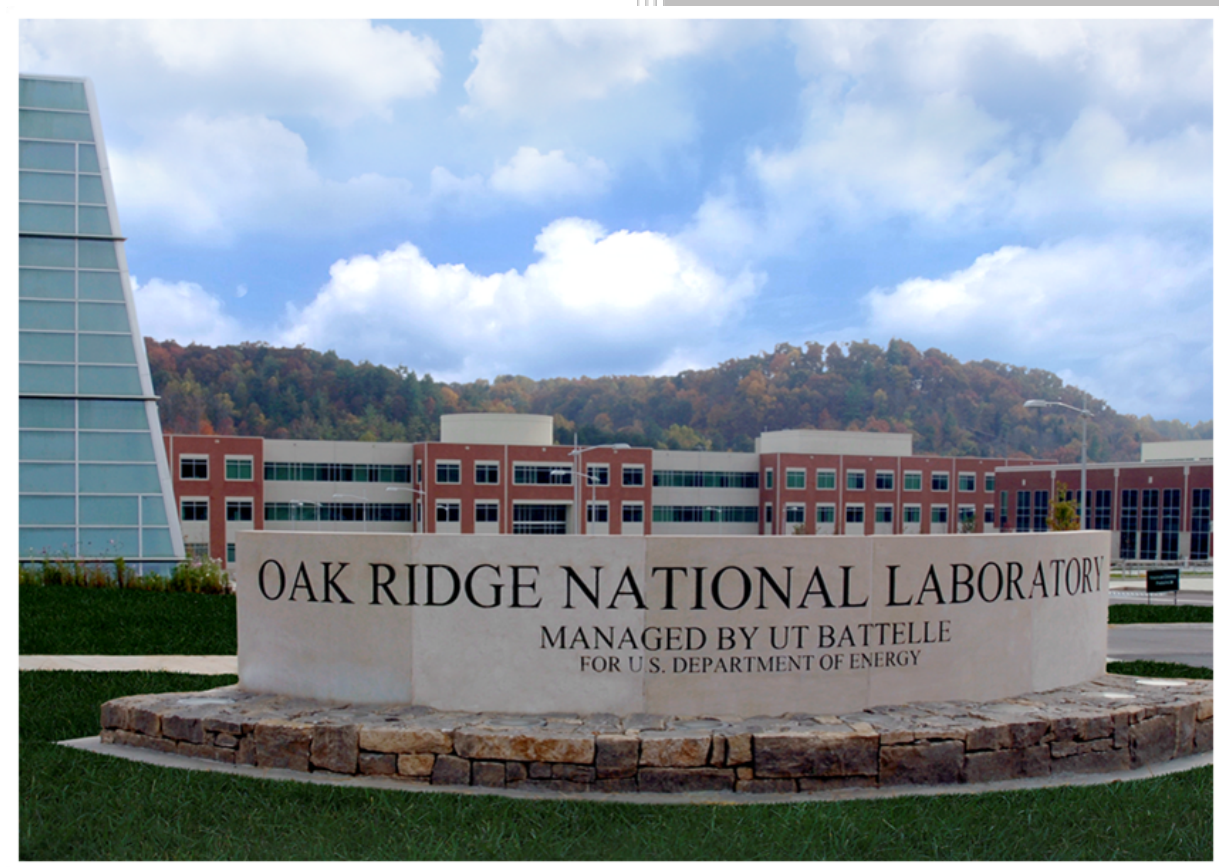

Meng-Dawn Cheng

Glenn Fugate

Jason Richards

Lee D. Trowbridge

October 28, 2019 


\section{DOCUMENT AVAILABILITY}

Reports produced after January 1, 1996, are generally available free via US Department of Energy (DOE) SciTech Connect.

Website www.osti.gov

Reports produced before January 1, 1996, may be purchased by members of the public from the following source:

National Technical Information Service

5285 Port Royal Road

Springfield, VA 22161

Telephone 703-605-6000 (1-800-553-6847)

TDD 703-487-4639

Fax 703-605-6900

E-mail info@ntis.gov

Website http://classic.ntis.gov/

Reports are available to DOE employees, DOE contractors, Energy Technology Data Exchange representatives, and International Nuclear Information System representatives from the following source:

Office of Scientific and Technical Information

PO Box 62

Oak Ridge, TN 37831

Telephone 865-576-8401

Fax 865-576-5728

E-mail reports@osti.gov

Website http://www.osti.gov/contact.html

This report was prepared as an account of work sponsored by an agency of the United States Government. Neither the United States Government nor any agency thereof, nor any of their employees, makes any warranty, express or implied, or assumes any legal liability or responsibility for the accuracy, completeness, or usefulness of any information, apparatus, product, or process disclosed, or represents that its use would not infringe privately owned rights. Reference herein to any specific commercial product, process, or service by trade name, trademark, manufacturer, or otherwise, does not necessarily constitute or imply its endorsement, recommendation, or favoring by the United States Government or any agency thereof. The views and opinions of authors expressed herein do not necessarily state or reflect those of the United States Government or any agency thereof. 


\title{
National Nuclear Security Administration
}

\section{CAPTURE OF URANIUM PARTICLES BY FILTRATION: Effects of Filter Material and Air Humidity}

Meng-Dawn Cheng, Glenn Fugate, Jason Richards, and Lee D. Trowbridge

Date Published: October 28, 2019

\author{
Prepared by \\ OAK RIDGE NATIONAL LABORATORY \\ Oak Ridge, TN 37831-6283 \\ managed by \\ UT-BATTELLE, LLC \\ for the \\ US DEPARTMENT OF ENERGY \\ under contract DE-AC05-00OR22725
}





\section{CONTENTS}

\section{Table of Contents}



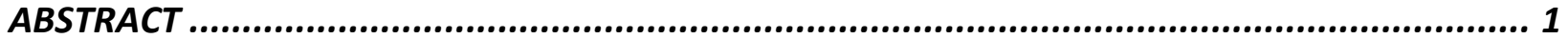

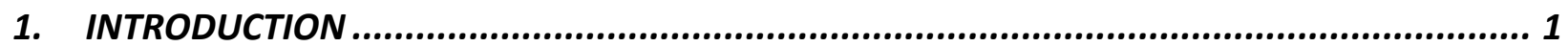

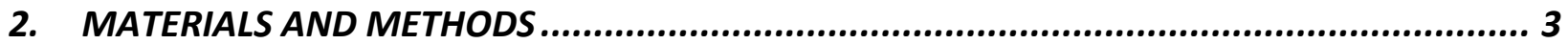

2.1 ENVIRONMENTAL EXPERIMENTAL CHAMBER (EEC) ......................................................... 4

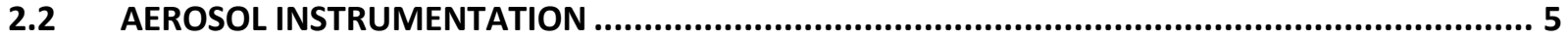

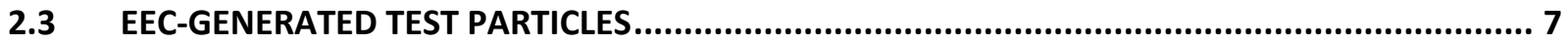

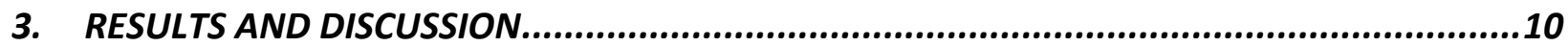

3.1 Effects of Filter Material on Standard HEPA Filters.............................................................10

3.2 Effects of Relative Humidity Conditions on Filter Performance ............................................11

3.3 Effects of Filter Performance Measured in Penetration Efficiency ......................................12

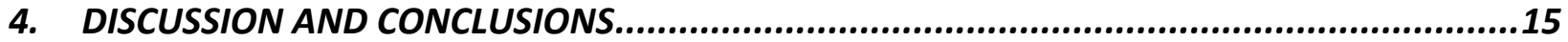

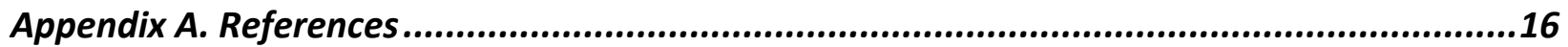




\section{Table of Figures}

Figure 1. Particle Removal Mechanisms of a Single Fiber (a) and Fiber Network (b) ............................ 1

Figure 2. ORNL Environmental Experimental Chamber (EEC) .........................................................

Figure 3. Irregular Structure of $\mathrm{UO}_{2} \mathrm{~F}_{2}$ Particles (adopted from Pickrell, 1985; $\mathrm{Rh}=\mathrm{XXXX \% )} \mathrm{..............} 7$

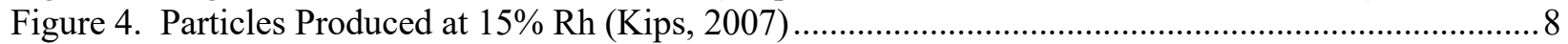

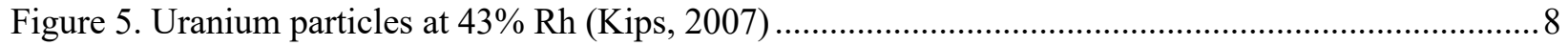

Figure 6. Uranium Particles Produced in 70\% Rh.............................................................................

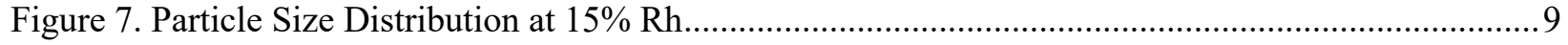



Figure 9. Size Distributions before and after a standard HEPA …...................................................... 10

Figure 10. Penetration Efficiency of HEPA Filter at Low Humidity Condition ....................................... 10

Figure 11. Size Distribution before and after a MERV9 Filter at 15\% Rh ............................................ 12

Figure 12. Size Distribution before and after a MERV9 Filter at 65\% Rh ........................................... 12

Figure 13. Size Distribution before and after the MERV10 filter at 15\% Rh ........................................ 12

Figure 14. Size Distributions before and after the MERV10 filters at 65\% Rh .................................... 12

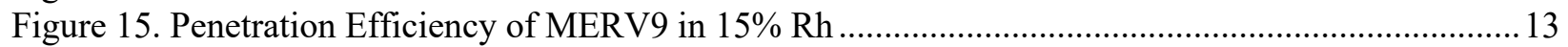

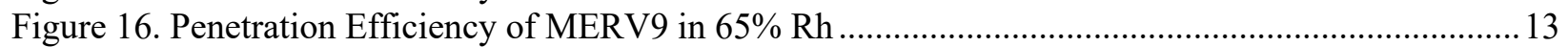

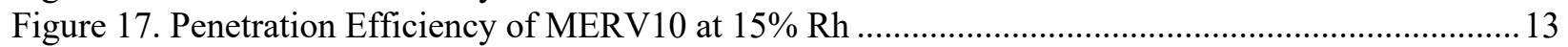

Figure 18. Penetration Efficiency of MERV10 at 65\% Rh ............................................................... 13 


\begin{abstract}
Filtration of airborne particles is a standard technique for removal of radiological particles from the effluent of a nuclear reactor. The effects of humidity on filter performance and uranium particles are however less understood. We have conducted experimental runs in the Environmental Experimental Chamber (EEC) located at ORNL to study the capture of uranyl fluoride particles in supports of NNSA missions. Two filter types, one of Minimum Efficiency Reporting Value (MERV)-9 and the other of MERV-10 American Society of Heating, Refrigerating and Air-Conditioning Engineering) ASHRAE rating, were used in the investigations under two humidity conditions $[15 \%$ and $65 \%$ Relative Humidity $(\mathrm{Rh})$ ]. Both MERV9 and MERV10 filters failed to capture uranyl fluoride particles that were smaller than $100 \mathrm{~nm}$. The penetration efficiencies for both filter types were very high, greater than $80 \%$, for particles from 10 to $100 \mathrm{~nm}$. As particles became larger and wetter, the capturing efficiencies of both types of filter improved. Slightly greater than $50 \%$ of particles from 1 to $10 \mu \mathrm{m}$ still escaped the capture by the MERV9 filters. However, MERV10 filters were able to capture higher than $50 \%$ of particles in the size range of 1 to $2 \mu \mathrm{m}$ indicating it is likely to meet ASHRAE requirements. Overall, the capture efficiency of a filter is highly dependent on uranyl fluoride particle size, which humidity plays a major role. These two filter types simply are unable to capture particles smaller than $1 \mu \mathrm{m}$. A filter that has a higher ASHRAE rating like the HEPA filter has to be used to capture sub-micron particles. Questions on how uranyl fluoride behave in a condition higher than $65 \% \mathrm{Rh}$ remain, because the particles could deliquescent at the higher humidity condition. That would complete change the size, shape, and surface properties of the uranyl fluoride particles which could lead to completely different filter performance and filtration dynamics. Furthermore, how high humidity affects filters of all MERV ratings remain unclear. Other filter characteristics such as surface charge could also be affected by high humidity condition and need to be investigated.
\end{abstract}




\section{INTRODUCTION}

Filtration of airborne particles is a standard technique for removal of airborne particles from the effluent of a source of particulate matter (PM) (e.g., coal-fired power plant, nuclear reactor, or combustion process that burns hydrocarbon fuels). There are several physical mechanisms contributing to the collection of particles by fibrous or fabric filters such as bag filters, commonly used in filtration. The main mechanisms are Brownian diffusion, interception, and inertial impaction; for each mechanism, the efficiency depends mainly on the particle size to collect. Figure 1 below depicts the particle removal mechanisms that include inertial impaction, interception, and diffusion onto a single fiber.

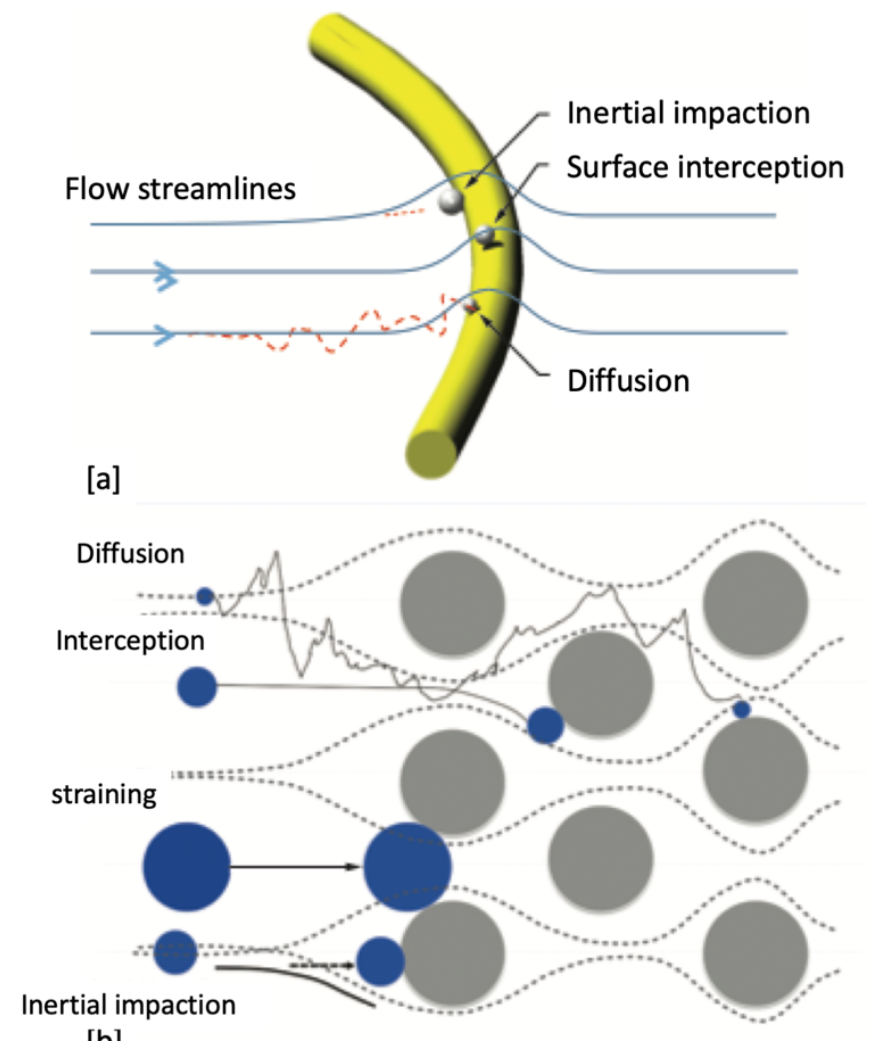

[b]

In addition to the three particle removal mechanisms known for a single fiber, particle sieving mechanism is also present in a fiber network that is actually the norm structure of a filter.

The solid particles deposited onto the filter media surface contribute to increase filtration efficiency (Thomas, et. al., 2001). The collected particles bridge together to form the so-called dust cake on the filter media. The formation and detachment of the dust cake from the filter surface influence the filtration 
performance of the bag filter. The structural properties of the dust cake, and so the ability of dust cake detachment, are influenced by different parameters such as filtration velocity or dust concentration (Cheng \& Tsai, 1998; Saleem \& Krammer, 2007) and probably the water content or humidity in the effluent air.

Typical commercial filters have a performance rating called the Minimum Efficiency Reporting Value (MERV) that is a value indicating the size of particles a filter is designed to capture. Higher MERV ratings are more effective at capturing smaller particles. Thus, hospitals tend to use MERV16 or higher, to capture the most pollutants possible. Although lower MERV rated filters are less efficient overall, they permit more air to go through the filter, which can improve the overall operation of the HVAC system (e.g., the facility energy efficiency, pressure drop, and or operating cost). It's highly important to have the perfect mix of air filter and MERV rating to meet the intended operational use. The American Society of Heating, Refrigerating and Air-Conditioning Engineers (ASHRAE), which designed the MERV rating, advises filters with minimum MERV ratings of 6. The U.S. Department of Energy recommends a minimum of MERV 13.

An air filter MERV rating has the following range (ASHRAE, 2018):

- MERV 1 to $4-<20 \%$ of large particles (3 to $10 \mu \mathrm{m})$ are captured

- MERV 5 to 7 - Between $20 \%$ and $69 \%$ of large particles (3 to $10 \mu \mathrm{m}$ ) are captured

- MERV 8 to 10 - Approximately $85 \%$ of large particles (3 to $10 \mu \mathrm{m}$ ) and $50 \%$ of small particles $(1.0$ to $3.0 \mu \mathrm{m})$ are captured

- MERV 11 to 16 - More than $90 \%$ of large particles (3 to $10 \mu \mathrm{m}$ ) and between $70 \%$ and $90 \%$ of small particles (1.0 to $3.0 \mu \mathrm{m})$ are captured

- MERV 17 to 20 - Even the smallest particles $(<0.3 \mu \mathrm{m})$ are captured

Thus, a filter rated MERV 9 should remove $85 \%$ of particles in the size range of ( 3 to $10 \mu \mathrm{m}$ ) and $50 \%$ of $(1.0$ to $3.0 \mu \mathrm{m})$, for instance. A MERV10 filter likewise should have a similar filtration capacity to that of MERV9 based on the above rating scale. The specifications for filters rated MERV9 or MERV10 did not mention the removal efficiency of particles smaller than $1 \mu \mathrm{m}$ or $1000 \mathrm{~nm}$. Then, a High Efficiency Particulate Air (HEPA) filter would have a MERV rating from 17 to 20. In other words, a HEPA filter is defined as a removal media that can remove $99.99 \%$ of the particulate matter of aerodynamic diameter of $300 \mathrm{~nm}$ or $0.3 \mu \mathrm{m}$.

Water vapor is a major component in the composition of air in source effluents; in addition, water vapor varies significantly with air temperature. The amount of water vapor in the air is called moisture or humidity, which is measured as Absolute Humidity ( $\mathrm{Ah}$ ) that is the mass concentration of water molecules for a given temperature or Relative Humidity $(\mathrm{Rh})$ that is the water vapor concentration at a given temperature in relation to the saturation water vapor concentration at that temperature. $\mathrm{Rh}$ is generally expressed in percentage, for example, an air of $15 \% \mathrm{Rh}$ is much drier than air of $65 \% \mathrm{Rh}$. At $293 \mathrm{~K}(20 \circ \mathrm{C}), 65 \% \mathrm{Rh}$ air contains $9.5 \mathrm{~g}$ of $\mathrm{H}_{2} \mathrm{O} / \mathrm{kg}$ of air while $15 \% \mathrm{Rh}$ air contains $2.19 \mathrm{~g} / \mathrm{kg}$ of air. A $400 \%$ more of air at $65 \% \mathrm{Rh}$ condition. Furthermore, air can hold more water vapor at a higher temperature than at a lower temperature. Thus, a $15 \% \mathrm{Rh}$ air contains $4.09 \mathrm{~g}$ of $\mathrm{H}_{2} \mathrm{O} / \mathrm{kg}$ of air in $303 \mathrm{~K}$ than $2.19 \mathrm{~g} / \mathrm{kg}$ in $293 \mathrm{~K}$ temperature, $87 \%$ more water molecules at $303 \mathrm{~K}$ than that in $293 \mathrm{~K}$ per $\mathrm{kg}$ of air, for example.

Humidity (i.e., water molecules) can alter particle characteristics thereby changing the filter performance. Humidity can also change filter characteristics leading to alteration of the filter performance. Boudhan et al. (2019) discovered that the pressure drop increases faster when a filter is clogged due to water capillary condensation effect that also led to better collection performance for particle of sizes in 110 to $300 \mathrm{~nm}$. 
Kim, et al. (2007) tested the filtration of $\mathrm{NaCl}$ nanoparticles (diameters ranged between 3 and $70 \mathrm{~nm}$ ) by a fiberglass filter. Their results demonstrated no significant influence of humidity on the filtration efficiency for Rh between $1 \%$ and $92 \%$ (i.e. 0.2 and $16 \mathrm{~g} / \mathrm{m}^{3}$ absolute humidity, AH). It is noted that $\mathrm{NaCl}$ particles deliquescent at 75\% Rh. However, Miguel (2003) observed an increase of fibrous filter efficiency with an increase of air humidity during the collection of aluminum particles in the size range of $0.8-6 \mu \mathrm{m}$, and it is noted that $\mathrm{Al}$ particles do not deliquescent.

The effect of air humidity on filtration performance and filtering media is not fully understood because it depends on several parameters such as the hygroscopicity of the particles, their size dynamics, the nature and size of the fibers and their ability to adsorb or absorb water, or the loaded mass of particles on the filter. The literature (Gupta, et al., 1993; Joubert, et al., 2010; Miguel, 2003; Montgomery, et al., 2015) shows that for a given mass of collected particles, the pressure drop of fibrous filters decreases with increasing humidity.

Ribeyre, et al. (2017) studied the influence of humidity on three different nanostructured filter cakes formed in dry air by three different non-hygroscopic nanoparticles. Their results showed that the filter pressure drop increases when the $\mathrm{Rh}$ increased gradually from $0 \%$ to $85 \%$. While Joubert, et al., (2011) showed that the exposure to a humid airflow of the loaded cake filter formed under dry conditions (with hygroscopic submicronic and non-hygroscopic micrometric particles) could lead to the reduction of the specific cake resistance i.e. a decrease in the filter pressure drop.

Besides the potential interactions of filter media materials with moisture that could change filtration characteristics, an additional issue on removal of airborne uranyl fluoride particles is that the particles are hygroscopic. The size and shape of the particles are subject to change in different humidity conditions (Bostick et al., 1984; Pickrell, 1985; Kips et al., 2007). As discussed earlier that filtration efficiency is particle size dependent, thus change of particle sizes by the moisture will alter the performance of a filter.

The objectives of our study were to investigate (1) the uranium particle removal by filtration using different types of filter media materials in the MERV ratings of 8-10 range and (2) the effects of relative humidity on the removal of uranyl fluoride particles. We focused on uranyl fluoride $\left(\mathrm{UO}_{2} \mathrm{~F}_{2}\right)$ particles because $\mathrm{UF}_{6}$ is the key ingredient in the making of nuclear fuels and $\mathrm{UF}_{6}$ hydrolysis produces uranyl fluoride particles.

\section{MATERIALS AND METHODS}

Referring to previous list of MERV rating that approximately $85 \%$ of large particles (in the diameter range of 3.0 to $10.0 \mu \mathrm{m})$ and $50 \%$ of small particles $(1.0$ to $3.0 \mu \mathrm{m})$ are captured by filters rated MERV9 and 10. The Sandia National Laboratory (SNL) produced and fabricated filters for test using materials that conform to MERV9 and MERV10 specifications. These SNL filters also met the operational requirements for testing at the ORNL Environmental Experimental Chamber (EEC). The filters tested were of the size of $15.24 \mathrm{~cm}$ by $15.24 \mathrm{~cm}$ by $2.54 \mathrm{~cm}$ thickness. A 105 feet per minute (FPM) face velocity was maintained throughout the tests at 750 SLPM flow rate was operated at the EEC. All the tests were performed at $298 \mathrm{~K}$ temperature and $2.18 \mathrm{~cm}$ of $\mathrm{H}_{2} \mathrm{O}$ pressure drop for MERV 10 and $1.37 \mathrm{~cm}$ of $\mathrm{H}_{2} \mathrm{O}$ pressure drop for MERV9. 


\subsection{ENVIRONMENTAL EXPERIMENTAL CHAMBER (EEC)}

The EEC (see Figure 2) is housed at Oak Ridge National Laboratory. The EEC is a recirculating, contained, temperature- and humidity-controlled system designed primarily to simulate an indoor industrial environment into which miniscule (i.e., fugitive emission level) $\mathrm{UF}_{6}$ or other pollutant releases of can be conducted. Controllable parameters are temperature, humidity, airflow, air dust loading and pollutant injection rate. The chamber provides the proper containment of the reaction products of the $\mathrm{UF}_{6}$ release for radiological and industrial hygiene purposes and is itself contained in a clean room to avoid undue influence from uncontrolled ambient dust on experimental samples. The EEC incorporates several means of analyzing the reaction products on-line during a release experiment (e.g., particle size distribution measurements via a Fast Mobility Particle Sizer (TSI Model 3091); HF concentration using a sensitive Picarro Cavity Ringdown Spectrometer, Model G2205). It also has several provisions for collect samples for post-experiment analysis (e.g., passive deposition substrate samples can be deployed for all or for part of the experiment; a series of electrostatic precipitators can concentrate particulate samples; an in-line filter position is available to allow examination of pre- vs. post-HEPA-filter reaction product loading in the air, on the electrostatic precipitators, on passive samples, or on the filter itself).

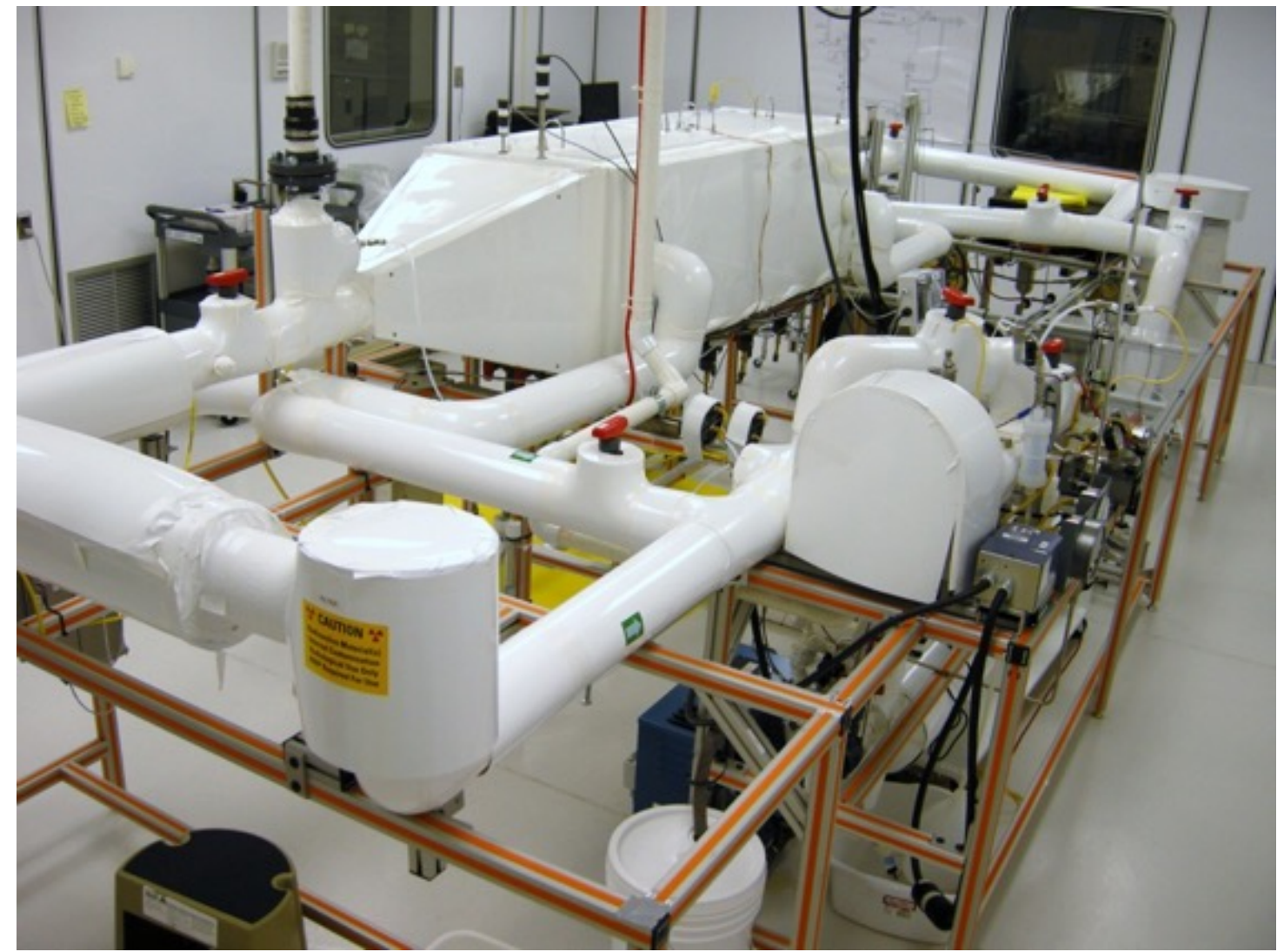

Figure 2. ORNL Environmental Experimental Chamber (EEC)

In the 2008 to 2012 timeframe, a significant number of release experiments were done under varying environmental conditions in which goals were to evaluate correlations between reaction product particle size and morphology with the environmental parameters of the releases. Later campaigns of smaller magnitude have been conducted in more recent years as well.

Physically, the EEC is not limited to the existing analytical infrastructure. The main drift chamber is a half-meter in height and width and about 2 meters long. It incorporates lids with multiple ports to allow 
additional hardware to be employed in the immediate vicinity of the leak or variable distances downstream, as is likely to be desired for this project. It does have a relatively low upper limit to the quantity of $\mathrm{UF}_{6}$ that can be used in a given experiment $(50 \mathrm{mg} \mathrm{U})$.

\subsection{AEROSOL INSTRUMENTATION}

Two real-time particle sizers were used in combination in the experiments to measure the particle size distribution from $6 \mathrm{~nm}$ to $20 \mu \mathrm{m}$ or $20,000 \mathrm{~nm}$. Both of these instruments were manufactured by the TSI, Inc. in Minnesota. The first instrument is the Fast Mobility Particle Sizer (FMPS, TSI Model 3091), while the other instrument is the Aerodynamic Particle Spectrometer (APS, TSI Model 3320, an earlier model of 3321). Both instruments were capable of measurement of 1 size distribution per second. The measurement interval in our experiments was set at 1 second per data point and averaged to 60 seconds for a sample.

FMPS (see Figure 3) consists of 22 electrodes and was operated at 10 LPM flow rate. Aerosol particles sampled in FMPS were charged by a unipolar charger before they enter the classifying region consisting of high-voltage electrodes as shown in Figure 4. Particle sizing resolution is 16 channels per decade (32 total). FMPS has a $1-\mu \mathrm{m}$ inlet to remove any particles larger than one micrometer in size. Aerosol particles are classified based on their corresponding electrical mobility. The sizing range for FMPS is approximately $5.6 \mathrm{~nm}$ to $560 \mathrm{~nm}$ and detailed technical specifications can be found in the literature at the following link: (https://www.tsi.com/getmedia/327799d1-909a-4cd5-a47b-a458c867ab36/3091-FMPSSpectrometer-Spec-Sheet-US?ext=.pdf).

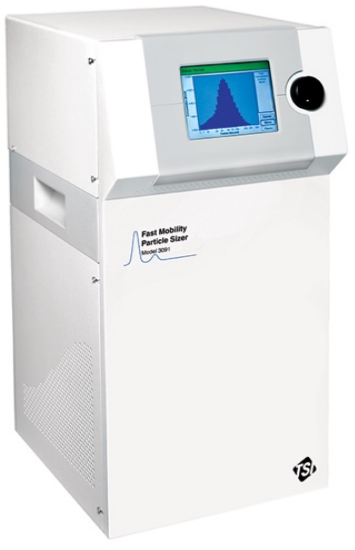

Figure 3. Photo of TSI Model 3091 FMPS

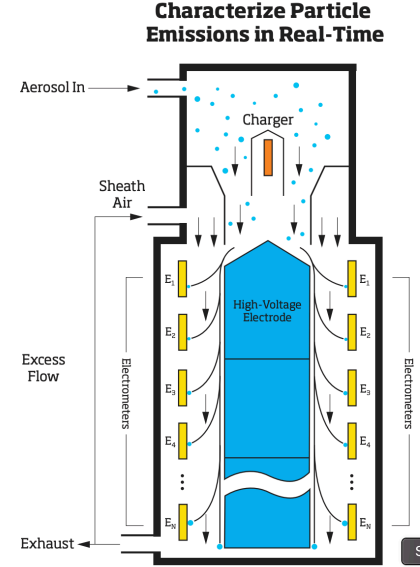

Figure 4. Schematics of Aerosol Flow in FMPS

The APS is shown in photo in Figure 5, and the flow schematics and detection region are shown in Figure 6. The sizing range of the APS is from 0.523 to $20 \mu \mathrm{m}$. The measurement interval for the APS was also 1 size distribution per second with the sampling flow rate into the APS at 5 LPM. One LPM is used for aerosol measurement and the other 4 are diverted through a particle filter to created particle-free sheath air as shown in Figure 6. Large particles (lower electrical mobility) are detected by the electrometers positioned at the lower end of the system, while small particles with higher electrical mobility are detected at the top (i.e., E1, E2, ... electrometers shown in Figure 4).

The APS 3321 is a time-of-flight spectrometer that measures the velocity of particles in an accelerating air flow through a nozzle. In the instrument, particles are confined to the centerline of an accelerating flow by sheath air. They pass through two broadly focused laser beams, scattering light as they do so. 
Side-scattered light is collected by an elliptical mirror that focuses the collected light onto a solid-state photodetector, which converts the light pulses to electrical pulses. By electronically timing between the peaks of the pulses, the velocity can be calculated for each individual particle. Velocity information is stored in 1024 time-of-flight bins. Using a polystyrene latex (PSL) sphere calibration, which is stored in non- volatile memory, the APS Model 3321 converts each time-of-flight measurement to an aerodynamic particle diameter. This particle size is binned into 52 channels (on a logarithmic scale).

Both instruments are atmospheric samplers, so they do not change the environmental conditions of the aerosol particles being collected. Furthermore, both instruments are sort of complementary in terms of the size region each instrument covers. The FMPS is from approximately 6 to $540 \mathrm{~nm}$, while the APS is from $523 \mathrm{~nm}$ to $20 \mu \mathrm{m}$. The small overlapping size region for both instruments were used in data reduction to provide a reliable sizing data for the underlying process. It is important to note that electrical mobility was produced by FMPS and aerodynamic diameter was by APS. There were two different physical quantities and a user has to understand the fundamental differences to be able to make a sound data reduction.

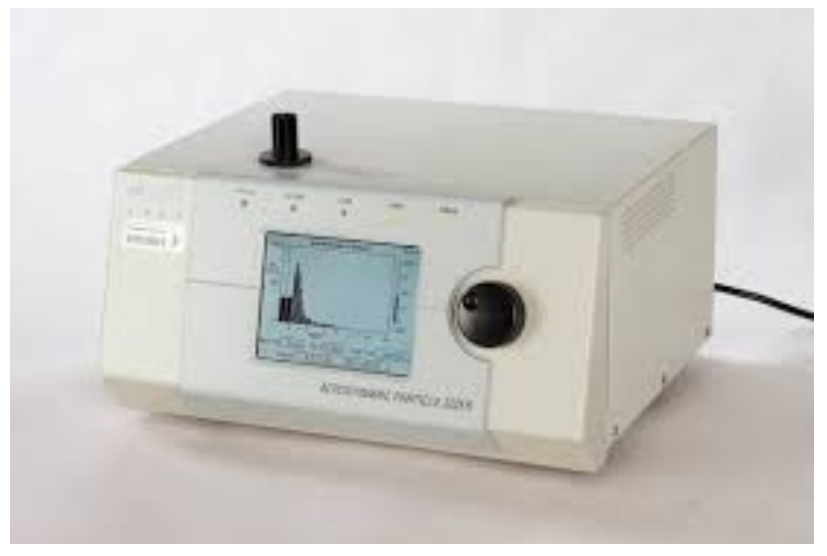

Figure 5. Photo of TSI Model 3021 APS

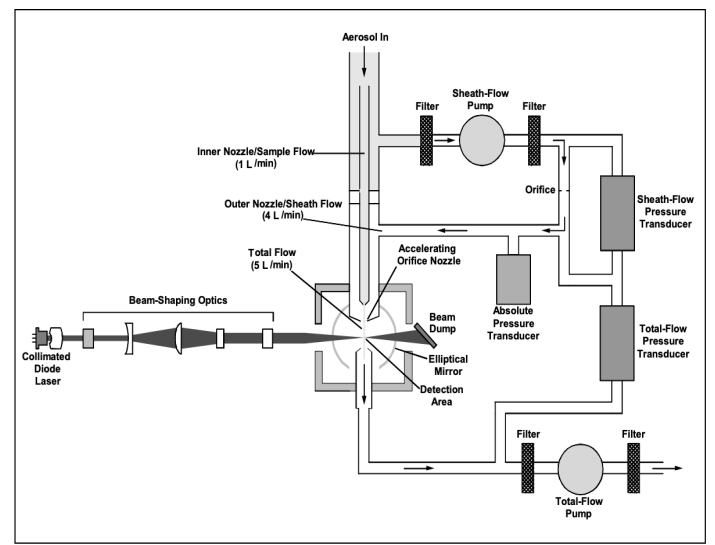

Figure 6. Schematics of APS

Particles counted at the top-end of the size distribution measured by the FMPS are often different in number from that counted at the tail-end of the same size distribution measured by the APS. To convert one diameter to another (i.e., to reconcile the APS diameter and FMPS diameter in the overlapped region), one needs to know the particle density and shape factor. Then the data from the overlapped region (e.g., 500-600 $\mathrm{nm}$ ) from both instruments were fitted using a spline function. The diameter conversion from aerodynamic diameter $\left(D_{p a}\right)$ to electrical mobility diameter $\left(D_{p m}\right)$ is

$$
D_{p a}=D_{p m}\left[\frac{C\left(D_{p m}\right)}{C\left(D_{p a}\right)}\right]^{1 / 2}\left(\frac{\varrho_{p}}{\chi \rho_{o}}\right)^{1 / 2}
$$

Where $\varrho_{p}$ is the particle density, and $\rho_{o}$ is the reference density of $1 \mathrm{~g} \mathrm{~cm}^{-3} \cdot \chi$ is the shape factor. $\mathrm{C}()$ is the slip correction that is given as

$$
C=1+\frac{2 \lambda}{D_{p i}}\left(1.142+0.558 e^{\frac{-0.999 D_{p i}}{2 \lambda}}\right)
$$

Where $\lambda$ is the mean free path with value of $6.65 \mathrm{E}-8 . \mathrm{D}_{\mathrm{pi}}$ is the particle diameter where the subscript equals to "a" for aerodynamic diameter and " $m$ " for mobility diameter. 


\subsection{EEC-GENERATED TEST PARTICLES}

The particles used for the tests were produced by $\mathrm{UF}_{6}$ hydrolysis in the EEC. $\mathrm{UF}_{6}$ hydrolysis generates $\mathrm{UO}_{2} \mathrm{~F}_{2}$ particles and hydrogen fluoride (HF) gas according to the overall reaction equation (1) as follows:

$\mathrm{UF}_{6(\mathrm{~g})}+2 \mathrm{H}_{2} \mathrm{O} \rightarrow \mathrm{UO}_{2} \mathrm{~F}_{2(\mathrm{~s})}+4 \mathrm{HF}_{(\mathrm{g})}$

Where $\mathrm{UF}_{6}, \mathrm{H}_{2} \mathrm{O}$, and $\mathrm{HF}$ are in the gas phase and $\mathrm{UO}_{2} \mathrm{~F}_{2}$ is the uranyl fluoride particles. The shape of $\mathrm{UO}_{2} \mathrm{~F}_{2}$ particles depends on the reaction conditions and has been observed as either irregular (as in branched chain) aggregates (Bostick et al., 1984; Pickrell, 1985) or spheroids (Bostick et al., 1984; Pickrell, 1985; Rips, 2007). Figures 7-10 show the general shapes of uranyl fluoride particles. The structural properties and morphologies of the particles are heavily dependent on the reaction conditions, particularly the molar ratio of $\mathrm{UF}_{6}$ and $\mathrm{H}_{2} \mathrm{O}$, for instance.

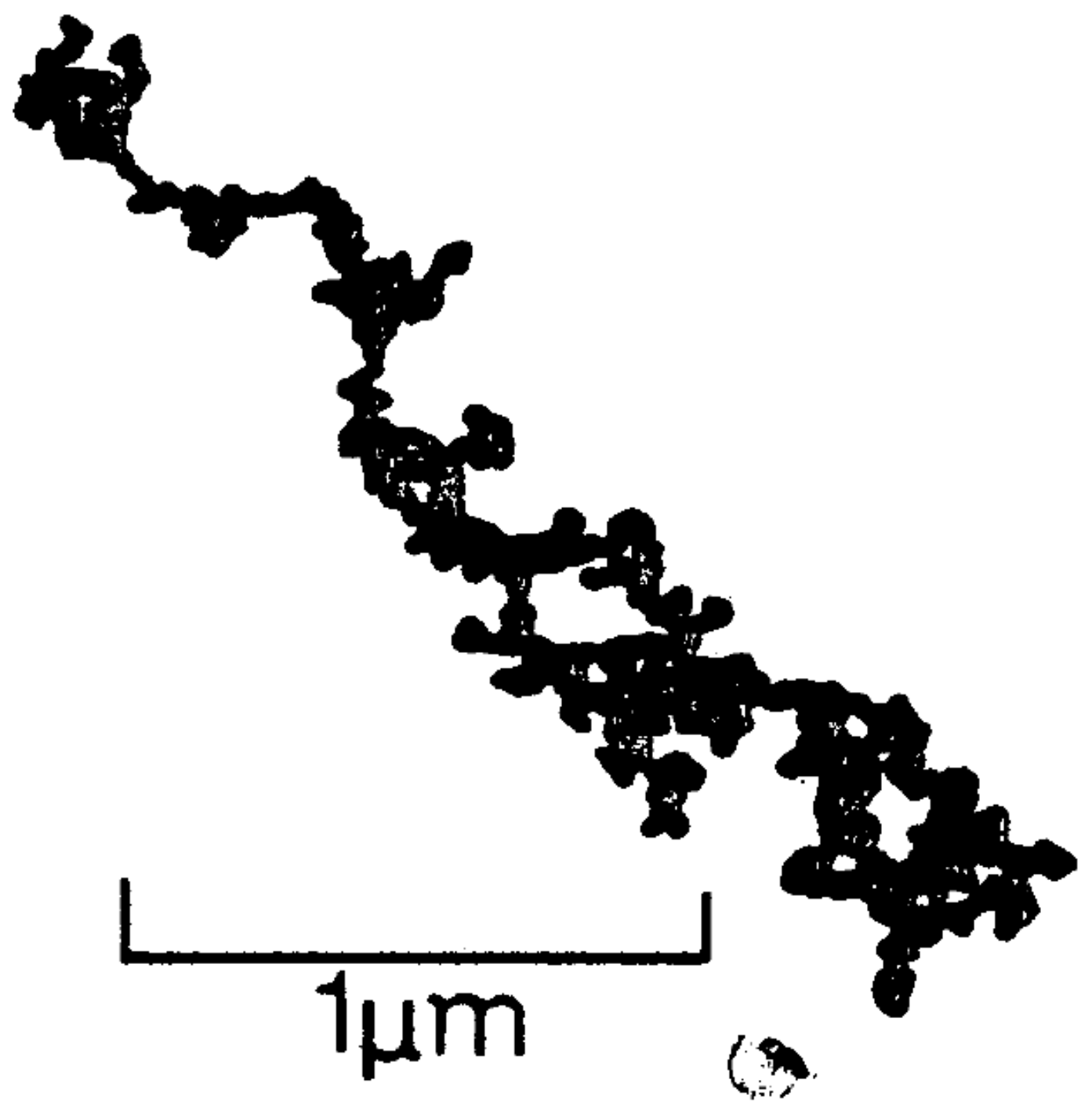

Figure 7. Irregular Structure of $\mathrm{UO}_{2} \mathrm{~F}_{2}$ Particles (adopted from Bostick et al., 1984, Rh<2\%) 

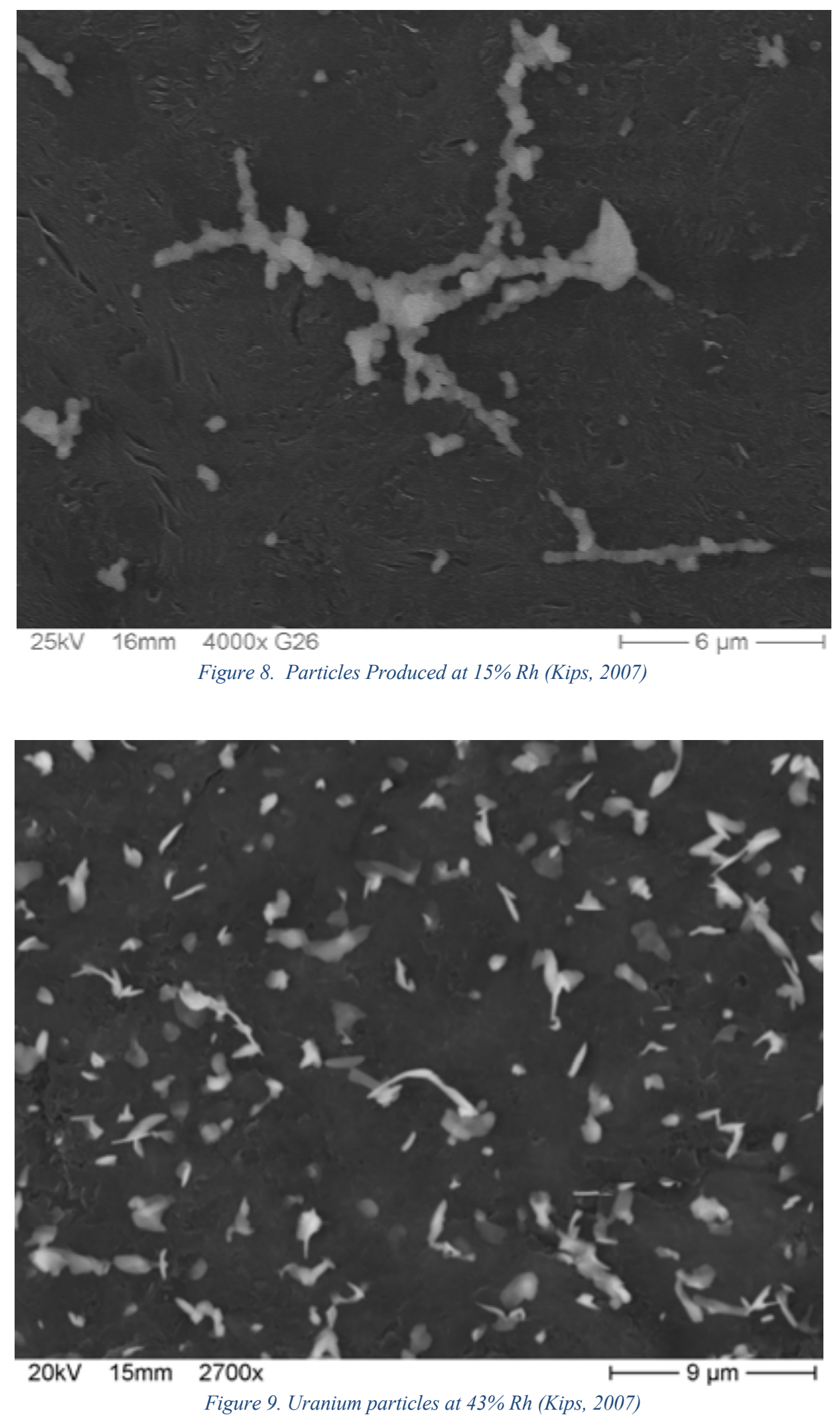


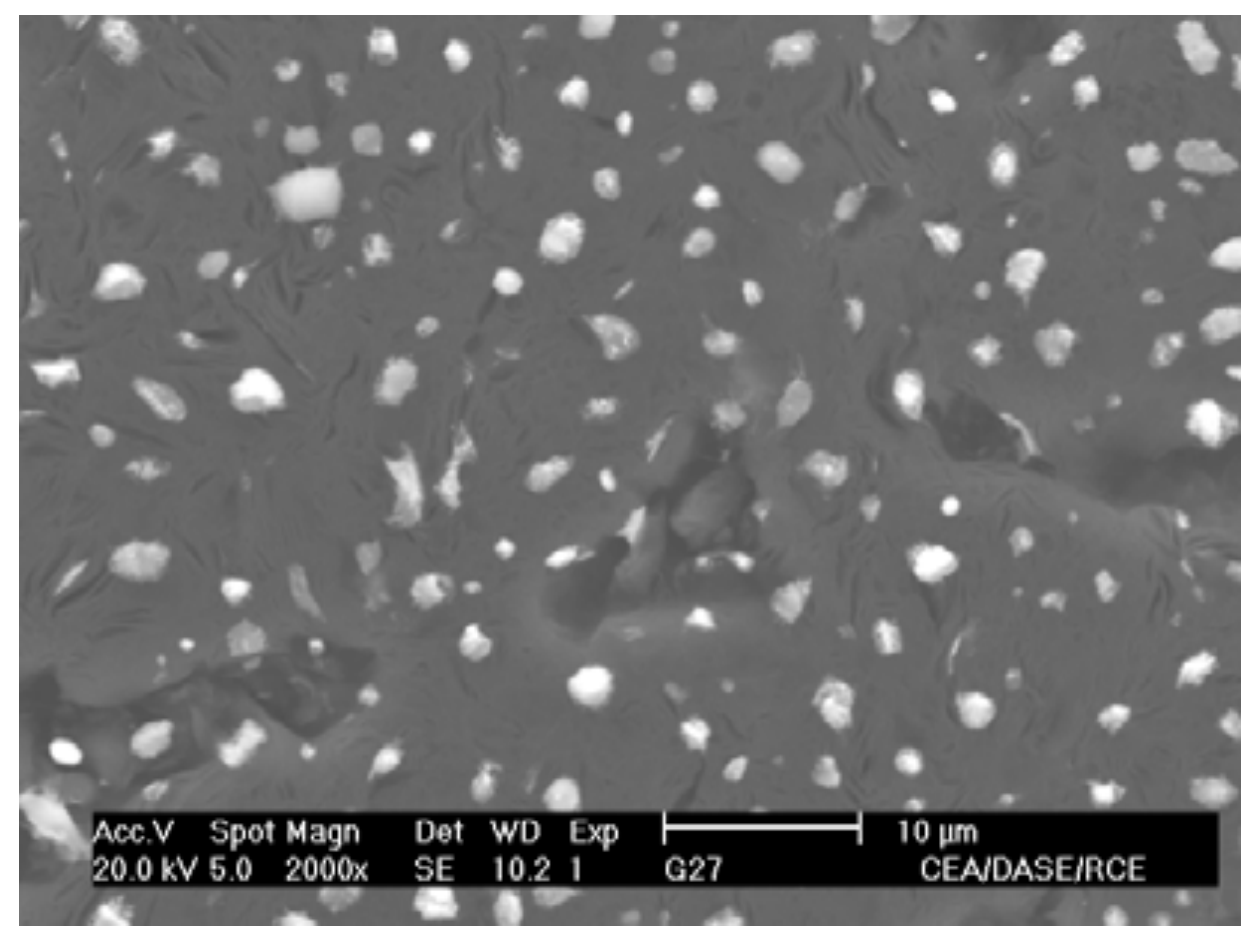

Figure 10. Uranium Particles Produced in $70 \%$ Rh

As the $\mathrm{Rh}$ increased, the produced $\mathrm{UO}_{2} \mathrm{~F}_{2}$ particles become more spheroids and less aggregated into a branch structure. Thus, from aerosol instrument point of view, the measured diameters of a particle population would be narrower as the $\mathrm{Rh}$ is increased. Therefore, in a drier condition, the measured particle size distribution could be broad. In addition to the shape and morphology of hydrolysis-produced individual particles, the population statistics of the produced particles provides a useful clue to the underlying physics and chemistry of the particle formation processes. For example, the particle size distributions measured in the EEC suggest consistently with the previous observations made by Kips (2007) that is high humidity produced more particles of similar shape (i.e., spheroids) and size; thus, resulting in a narrow size distribution. Two size distributions are shown in the following Figure 11 for $15 \% \mathrm{Rh}$ and Figure 12 for $65 \% \mathrm{Rh}$, respectively.

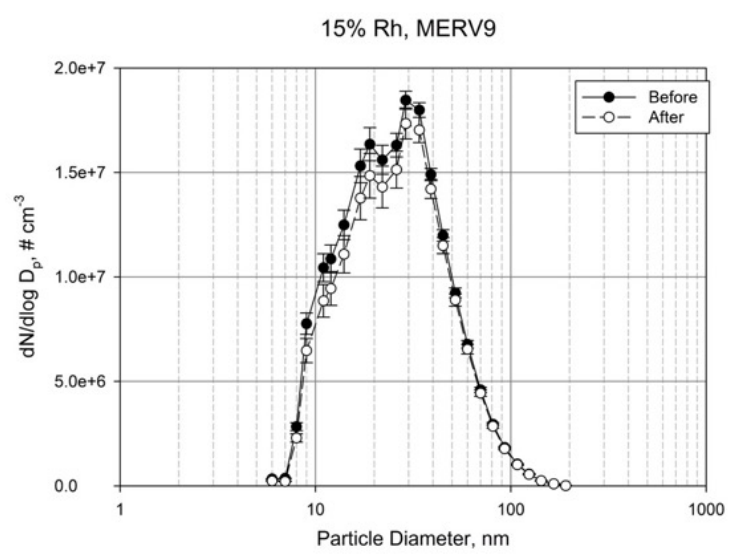

Figure 11. Particle Size Distribution at $15 \%$ Rh

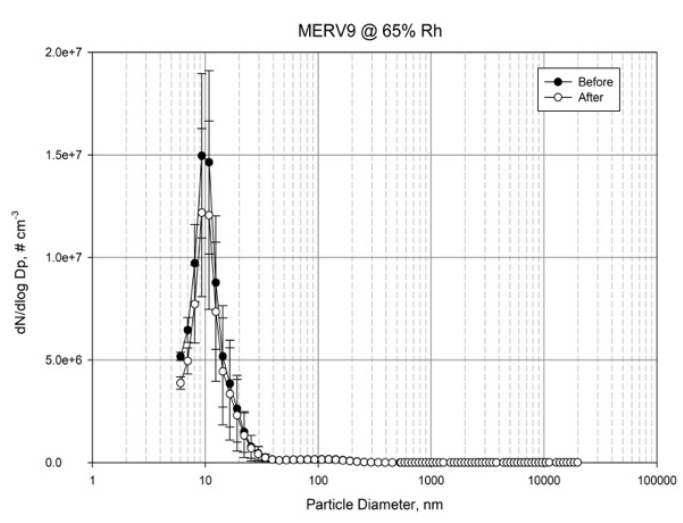

Figure 12. Particle Size Distribution at $65 \%$ Rh

Note that the shapes of the particle size distribution in Figures 11 and 12 are substantially different. The distribution at low humidity was broad and the size was spanning from $8 \mathrm{~nm}$ to $200 \mathrm{~nm}$ as shown in 
Figure 11, while it was narrow at the higher humidity with the size spanning from $8 \mathrm{~nm}$ to $50 \mathrm{~nm}$ plus additional particles larger than $100 \mathrm{~nm}$ as shown in Figure 12. The peak heights at both humidity conditions were approximately identical at $1.5 \times 10^{7}$ per mL, but the Full Width Half Maximum (FWHM) that measures the size distribution spread for the $15 \% \mathrm{Rh}$ condition was about $42 \mathrm{~nm}$ while that for the major peak in the $65 \% \mathrm{Rh}$ was $4 \mathrm{~nm}$. $\mathrm{UO}_{2} \mathrm{~F}_{2}$ articles produced at the lower humidity were small, centered at $30 \mathrm{~nm}$ and the largest registered by our FMPS instrument was less than $100 \mathrm{~nm}$. At the higher humidity $(65 \% \mathrm{Rh})$ condition, particles tend to be centered around $10 \mathrm{~nm}$. Particles with diameters larger greater than $100 \mathrm{~nm}$ (with much less number concentration) were observed at the higher humidity but not at lower humidity. These distinctions suggest that the final shape and size of the particles observed in EEC in the $65 \% \mathrm{Rh}$ condition were likely to be the result of coalescence at the high humidity, while those in the $15 \% \mathrm{Rh}$ condition were probably resulted from aggregation and or coagulation. These aerosol dynamic processes in different humidity conditions play the key role in shaping the final morphology of the $\mathrm{UO}_{2} \mathrm{~F}_{2}$ particles before the filter and therefore affecting the performance of the filters.

\section{RESULTS AND DISCUSSION}

\subsection{EFFECTS OF FILTER MATERIAL ON STANDARD HEPA FILTERS}

The effect of filter material on the performance of a filter was investigated in a dry condition (i.e., at $15 \%$ $\mathrm{Rh}$ ), since HEPA filters are primarily used in nuclear facilities to capture small particles like those produced in the dry conditions. Removal of $\mathrm{UO}_{2} \mathrm{~F}_{2}$ particles in EEC by HEPA filters was presented here as a reference to the results of other filters. The particle size distributions, one for "before" and the other for "after", from experiments with standard HEPA filters are shown in Figure 13. The curve in Figure 13 for "before" (the open circles) is similar to that "before" curve shown in Figure 11. The "after-curve" (the closed circles) in Figure 13 shows all particles in the size range of 8 to $200 \mathrm{~nm}$ range were completed removed by HEPA filters. The curve in Figure 14 shows the penetration efficiency of particles through the HEPA filters, which is nearly zero for particles from 8 to about $250 \mathrm{~nm}$. In other words, the removal efficiency of the HEPA filter for all particles in the $(8-250 \mathrm{~nm})$ size range was $100 \%$ that is consistent with the MERV rating of a HEPA filter performance.

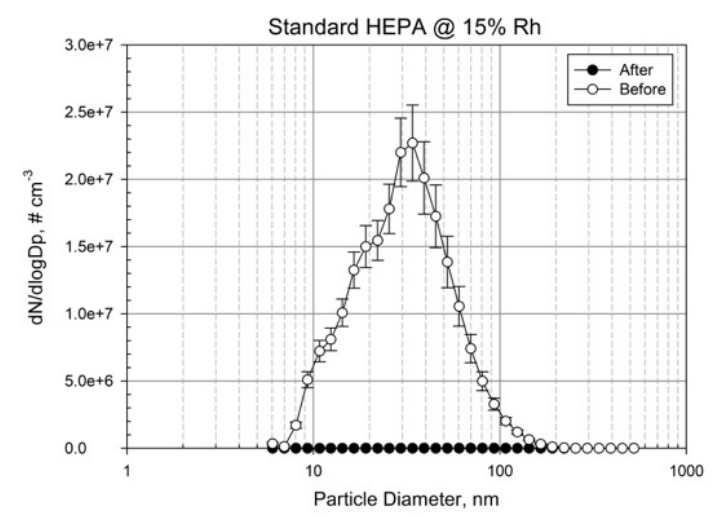

Figure 13. Size Distributions before and after a standard HEPA

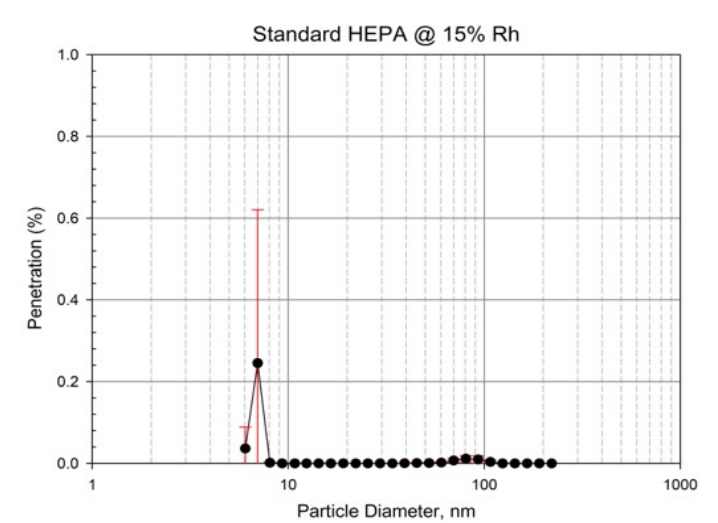

Figure 14. Penetration Efficiency of HEPA Filter at Low Humidity Condition 
We did not investigate HEPA filtration performance for the $65 \%$ Rh condition because sizes of particles produced in higher humidity conditions are either in a similar size range to that at the $15 \% \mathrm{Rh}$ condition or larger. Thus, we expect the penetration curve for a HEPA filter at the $65 \% \mathrm{Rh}$ condition would be similar to or better than that shown in Figure 14.

\subsection{EFFECTS OF RELATIVE HUMIDITY CONDITIONS ON FILTER PERFORMANCE}

We presented the effects of relative humidity on filter performance in this section. The size distributions of particles before the filters and after they passed through the filters are presented in Figures $15-19$. Multiple instrument scans of the particle size distributions were taken for before and after positions under each experimental condition. In fact, nine to sixteen size distributions were scanned for the pre- or postfilter condition in each experiment. The curves plotted in the figures represent the average size distributions, while the standard deviation of the curves in each experiment were calculated as the error bars plotted in the figures. The size distributions measured before the filters were those of the hydrolysisproduced particles or the "source" particles. Since the source particles were produced by UF $_{6}$ hydrolysis in the EEC flow, they were expected to have some variations because of the inherent nature of variability in a chemical reaction not to mention the reaction occurred in a reasonably large volume of the EEC. For example, Figure 17 shows the distribution pairs taken on different days for the same $15 \% \mathrm{Rh}$ condition. The 4 distribution pairs differ by $2 \mathrm{X}$ from one run to another.

The hydrolysis produced particles in the $15 \% \mathrm{Rh}$ conditions have size distributions that are broader (Figures 15 and 17) than those in the 65\% Rh conditions (Figures 16 and 18). Since Rh was the primary factor differentiating $15 \%$ from $65 \%$ Rh conditions, we had to conclude that humidity did play a major role in controlling the particle sizes in the filtration experiments. Assuming all initially formed uranyloxide particles were approximately the same size, particles coagulated and aggregated leading to a spread in the size distribution (i.e., a broad distribution) in the dryer condition ( $15 \% \mathrm{Rh})$. In the wetter condition $(65 \% \mathrm{Rh})$, water molecules were uptake by uranyl fluoride particles from which particles would shape more like spheroids or round singlets (as opposed to a branched structure like those shown in Figure 7) leading to a narrow size distribution. Since the peak locations of the distributions in the $65 \% \mathrm{Rh}$ condition were approximately $10 \mathrm{~nm}$, this sets a boundary condition on the upper bound of the size of the initially formed uranyl fluorides particles. In other words, the initially formed uranyl fluorides should be less than or equal to $10 \mathrm{~nm}$ in diameter. Our sister NNSA/NA20 project titled "Uranium Particle Formation" is being executed to verify this initial condition.

The effects of filter performance on particles are displayed in Figure 15 for $15 \%$ Rh and Figure 16 for $65 \% \mathrm{Rh}$ for the MERV9 filters, and Figure 17 and 18 for MERV10 for $15 \%$ and $65 \% \mathrm{Rh}$, respectively. If a pair of particle size distributions before and after a filter were close or even overlapping, it would be a clear indication that the filter had poor performance because most, if not all, particles penetrate the filters. For the 15\% Rh condition (Figure 15), most particles penetrated MERV9 filters, a minor fraction of particles in between 10 and $30 \mathrm{~nm}$ were captured by the filters. Similar observation in particle penetration through MERV10 filters (Figure 17) was found with the exception that the captured fraction of 10-30 nm particles by MERV10 filters was higher than that by the MERV9 filters. In the $65 \%$ Rh conditions, the data exhibit high scattering that makes it statistically difficult to decipher the removal capabilities of the filters. We suspected that the steam generator that was used in EEC to manipulate and maintain the desired Rh might be the operational cause of the run-by-run scatter for the high Rh conditions. However, from the averaged outcomes shown in Figures 16 and 18, the capture efficiencies for both filter types were low for particles smaller than $50 \mathrm{~nm}$, but higher than $50 \%$ for super-micron particles.

Multiple distributions were plotted in Figures 17 and 18 to show particle size distributions before and after the filters, and the variations among the curves under the same Rh condition could be seen. The 


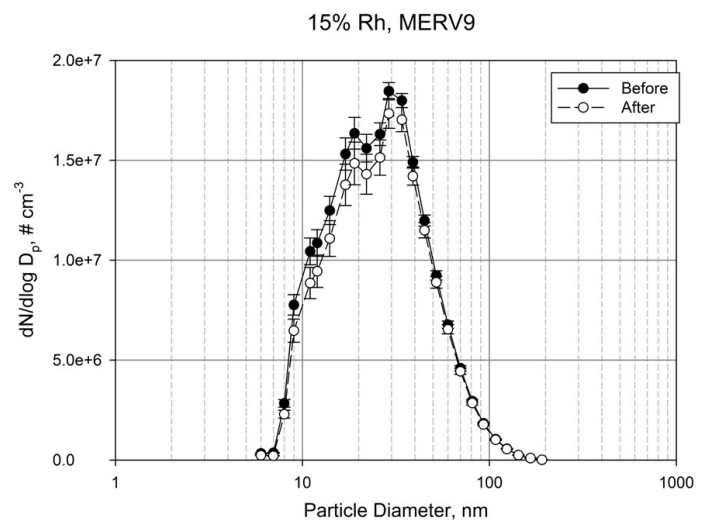

Figure 15. Size Distribution before and after a MERV9 Filter at $15 \%$ Rh

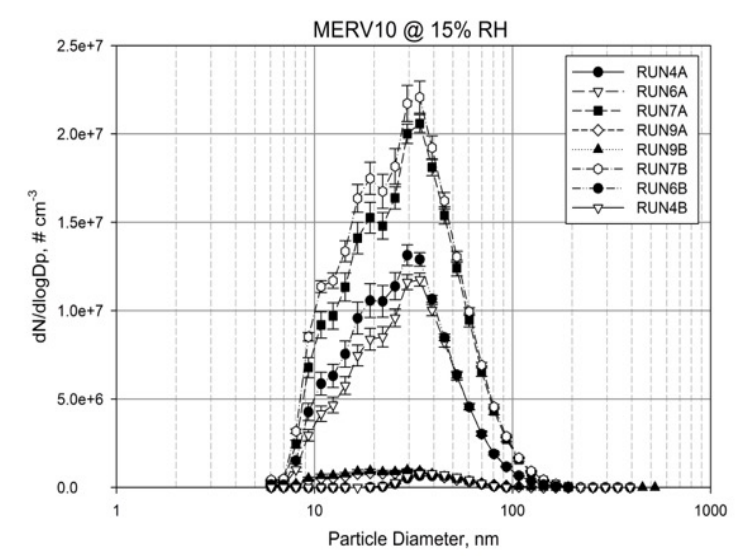

Figure 17. Size Distribution before and after the MERV10 filter at $15 \% \mathrm{Rh}$

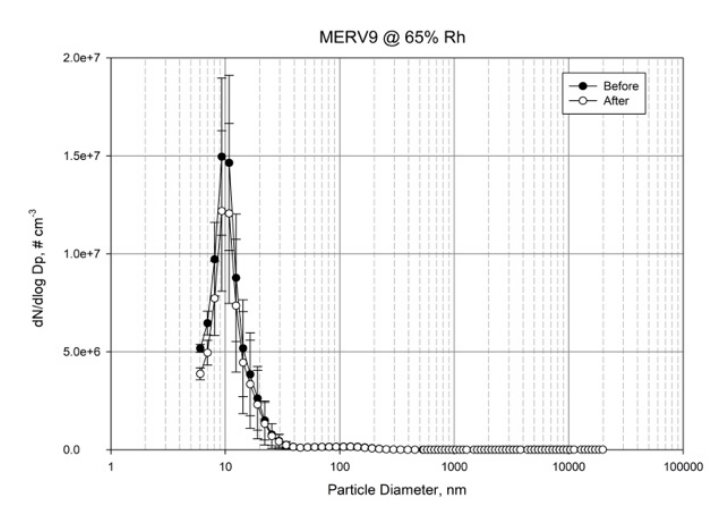

Figure 16. Size Distribution before and after a MERV9 Filter at $65 \%$ Rh



Figure 18. Size Distributions before and after the MERV10 filters at $65 \% \mathrm{Rh}$

error bars associated with the particle size distributions in the dry conditions were smaller than those in the wet conditions; thus, one clearly see that the uranyl fluoride particles produced by the same hydrolysis reaction varied significantly on different dates [see the 4 runs (Run4, 6, 7, and 9) in Figures 17]. Similar observation exists for the wet conditions, but the error bars were large, which reduced the statistical power in deciphering the variation embedded in the size distributions over different runs. The average results in Figure 18 however indicate that run-by-run variations did exist.

\subsection{EFFECTS OF FILTER PERFORMANCE MEASURED IN PENETRATION EFFICIENCY}

Due to the inherent variation of particle size distributions from one run to another described in the last section (Section 3.2), we show another way to measure filter performance for particle removal by using an index called the penetration efficiency for a filter as defined in the following equation (2):

$\eta=\frac{N_{0}}{N_{i}}$

Where $\eta$ is the penetration efficiency or fraction with a numeric value between 0 and 1 , a value of 0 indicates $100 \%$ removal while a value of 1 indicates no removal of any particles entering a filter. No is the number concentration of particles after the filter and $\mathrm{Ni}$ is that before. In other words, the removal efficiency has a value of $(1-\eta)$. The penetration efficiency can be calculated individually for each run 
eliminating the run-to-run variation issue associated with the particle size distributions. Moreover, it is expected that the penetration efficiency would be less sensitive to the run-to-run variation than the original particle size distributions shown in Figures 15 to 19, which would be anticipated to provide a clear indication on the filter performance as a function of relative humidity and particle size.

The calculated penetration efficiencies for the filter types at the two Rh conditions were shown in Figures $19-23$.

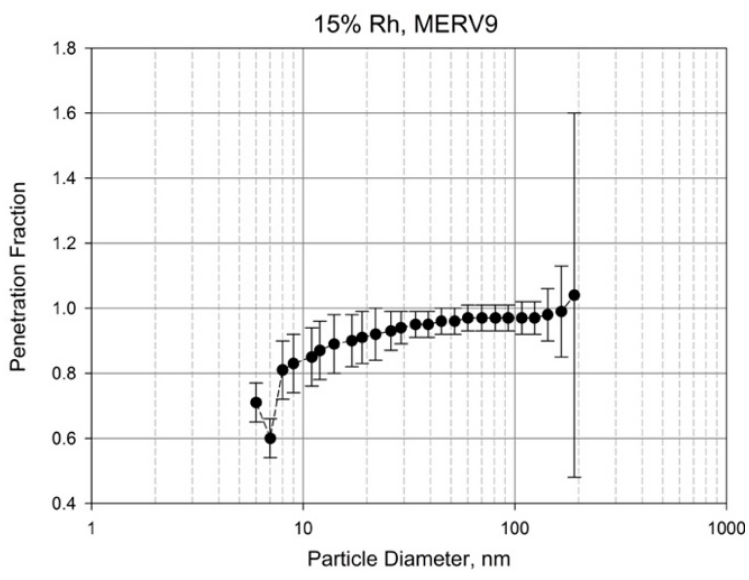

Figure 19. Penetration Efficiency of MERV9 in $15 \%$ Rh

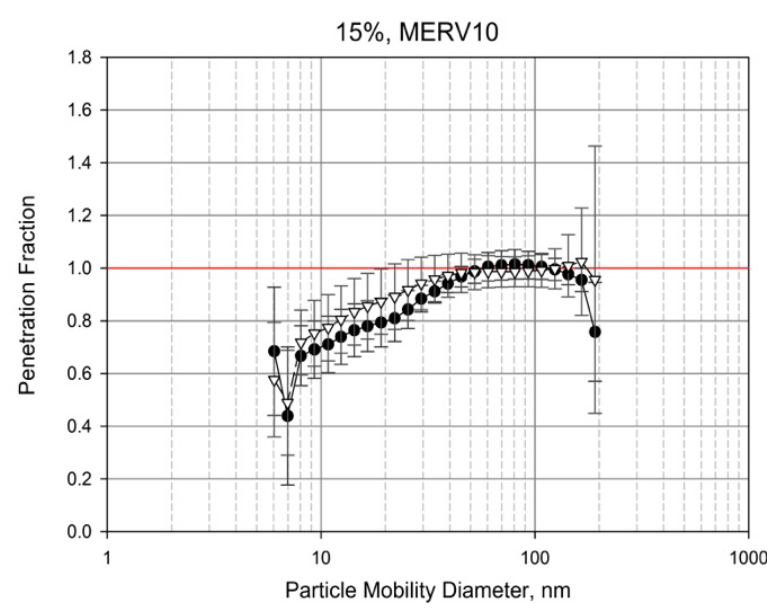

Figure 21. Penetration Efficiency of MERV10 at $15 \%$ Rh

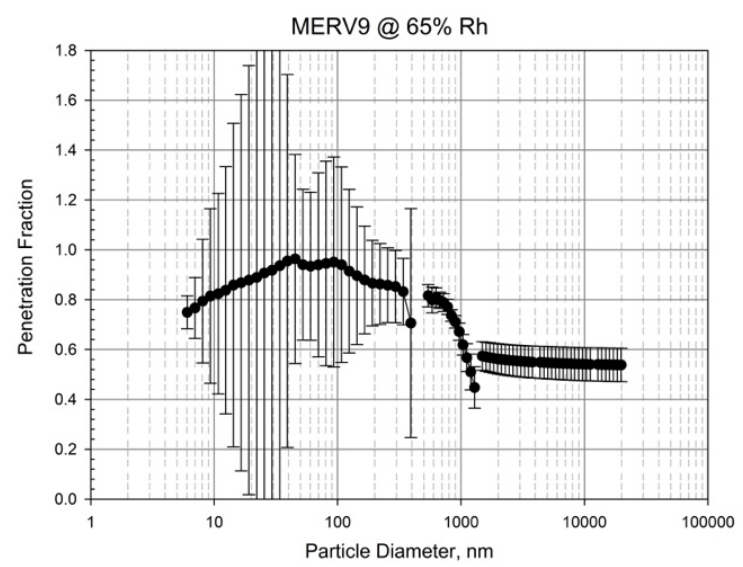

Figure 20. Penetration Efficiency of MERV9 in $65 \%$ Rh

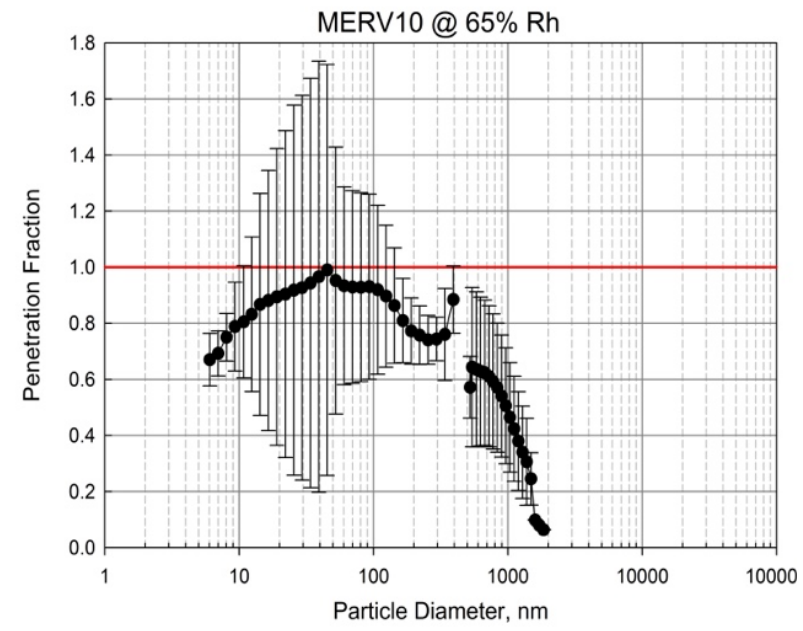

Figure 22. Penetration Efficiency of MERV10 at $65 \%$ Rh

The penetration efficiency for MERV9 in 15\% Rh condition is shown in Figure 19 and in $65 \% \mathrm{Rh}$ condition in Figure 20, and that for MERV10 in Figures 21 and 22, respectively. Remember that MERV9- and MERV10-class of filters are supposed to be able to remove $85 \%$ of particles in the size range of ( 3 to $10 \mu \mathrm{m})$ and $50 \%$ of $(1.0$ to $3.0 \mu \mathrm{m})$. A MERV10 filter likewise should have a similar filtration capacity to that of MERV9 based on the ASHRAE rating.

It is noted that the hydrolysis reaction in $15 \% \mathrm{Rh}$ condition in EEC did not produce any particles larger than 1,000 $\mathrm{nm}(1 \mu \mathrm{m})$. Thus, we expected the penetration efficiencies of the MERV9 and MERV10 filters to be greater than $50 \%$ in the dry condition. The results shown in Figure 19 and 21 supported the 
expectation. In other words, more than $50 \%$ of particles smaller than $1,000 \mathrm{~nm}$ were not captured by these two types of filters in the dry conditions. Interestingly for the size range in between 10 and $100 \mathrm{~nm}$ as shown in Figure 19 and 21 in the 15\% Rh conditions, the larger the diameter of the uranyl fluoride particles, the higher the penetration efficiency for both types of filter. Similar observations of this trend were found in Figures 20 and 22 for the $65 \%$ Rh condition. We conclude that these two filter types simply could not remove particles in the diameter range of 10-100 nm, effectively, irrespective of humidity condition.

When the size of particles was greater than $100 \mathrm{~nm}$, only produced under a higher relative humidity condition like $65 \% \mathrm{Rh}$, the particle penetration efficiencies decreased as particle diameter increased from $100 \mathrm{~nm}$ to $2,000 \mathrm{~nm}$ (i.e., 0.1 to $2 \mu \mathrm{m}$ ) as shown in Figures 20 and 22. Remember the ASHRAE rating for these two filter types is 50\% removal for particles in the size range of 1 to $3 \mu \mathrm{m}$. MERV9 showed slightly greater than $50 \%$ of particles greater than $1 \mu \mathrm{m}$ escaped the filter capture. In other words, the MERV9 filters tested did NOT meet the ASHRAE standard, strictly. MERV10 filters, on the other hand, captured 50 to $80 \%$ of particles in the size range of 1 to $2 \mu \mathrm{m}$, which conform to the ASHRAE rating, but greater than $50 \%$ of particles that were smaller than $1 \mu \mathrm{m}$ went through the MERV10 filters. 


\section{DISCUSSION AND CONCLUSIONS}

We have conducted experimental runs in the Environmental Experimental Chamber (EEC) located at ORNL to study the capture of uranyl fluoride particles using filtration technique in support of NNSA missions. Two humidity conditions $(15 \%$ and $65 \% \mathrm{Rh})$ were investigated and two filter types, one of MERV-9 and the other of MERV-10 ASHRAE rating, were used. The study has produced the following observations and conclusions:

1. The $\mathrm{UF}_{6}$ hydrolysis reaction in the EEC produced uranyl fluoride particles for the filter tests as required in the dry (or 15\% Rh) condition. However, the size distribution of uranyl fluoride particles varied significantly from one experimental run to another in the wetter condition (or $65 \% \mathrm{Rh}$ ).

2. All the uranyl fluoride particles produced in the $15 \% \mathrm{Rh}$ condition were less than $200 \mathrm{~nm}$ and have a broad size distribution or widely dispersed sizes. At higher humidity (i.e., 65\% Rh), particle grew and larger than $1,000 \mathrm{~nm}$ particles could be observed. In high humidity condition, particles smaller than $100 \mathrm{~nm}$ have a narrow size distribution.

3. Based on the previous studies, we also concluded that the particle morphology reflects the humidity condition that uranyl fluoride particles actually experienced in the reaction. At a lower humidity, particles tend to aggregate and produce a broad size distribution. On the other hand, at a higher humidity like $65 \% \mathrm{Rh}$, particles are potentially coated with water vapor molecules and tend to be in spheroid shape leading to a narrow size distribution. The condensation and uptake of water vapor by the uranyl fluoride particles also produced super-micron size particles that we did not observed in the $15 \% \mathrm{Rh}$.

4. Both MERV9 and MERV10 filters failed to capture uranyl fluoride particles that were smaller than $100 \mathrm{~nm}$. The penetration efficiencies for both filter types were greater than $80 \%$, for particles from 10 to $100 \mathrm{~nm}$.

5. As particles became larger and wetter, the capturing efficiencies of both types of filter improved. Slightly greater than $50 \%$ of particles from 1 to $10 \mu \mathrm{m}$ still escaped the capture by the MERV9 filters. However, MERV10 filters were able to capture higher than $50 \%$ of particles in the size range of 1 to $2 \mu \mathrm{m}$ indicating it is likely ASHRAE compliant.

6. Overall, the capture efficiency of a filter is highly dependent on particle size. These two filter types simply are unable to capture particles smaller than $1 \mu \mathrm{m}$. A filter that has a higher ASHRAE rating like the HEPA filter has to be used to capture sub-micron particles.

Questions on how uranyl fluorides behave in a humidity condition higher than $65 \%$ remain, because the particles could deliquescent at the higher humidity condition. That would complete change the size, shape, and surface properties of the uranyl fluoride particles which could lead to completely different filter performance and filtration dynamics. Other filter characteristics such as surface charge could also be affected by the humidity condition and need to be investigated. 


\section{APPENDIX A. REFERENCES}

1. ASHRAE (2018) Understanding MERV, https://www.nafahq.org/understanding-merv/.

2. Bostick, W.D., W.H. McCulla, P.W. Pickrell, and D.A. Branam (1984) Sampling and characterization of aerosols formed in the atmospheric hydrolysis of $U F_{6}, \mathrm{~K} / \mathrm{PS}-5027, \mathrm{CONF}-$ 831025-22, Report of Martin Marietta Energy Systems, Inc., Oak Ridge Gaseous Diffusion Plant, Oak Ridge, TN 37830.

3. Boudhan, R., A. Joubert, S. Durecu, K. Gueraoui, and L. Le Coq. (2019) Influence of air humidity on particle filtration performance of a pulse-jet bag filter, Journal of Aerosol Science, 130: pp.1-9.

4. Cheng, Y.-H. \& C. J. Tsai (1998) Factors influencing pressure drop through a dust cake during filtration, Aerosol Science \& Technology, 29: 315-328.

5. Gupta, A., Novick, V. J., Biswas, P., \& Monson, P. R. (1993). Effect of humidity and particle hygroscopicity on the mass loading capacity of high efficiency particulate air (HEPA) filter. Aerosol Science and Technology, 19, 94-107.

6. Joubert, A., Laborde, J. C., Bouilloux, L., Callé-Chazelet, S., \& Thomas, D. (2010). Influence of humidity on clogging of flat and pleated HEPA filters. Aerosol Science and Technology, 44, 10651076.

7. Joubert, A., Laborde, J. C., Bouilloux, L., Chazelet, S., \& Thomas, D. (2011). Modelling the pressure drop across HEPA filters during cake filtration in the presence of humidity. Chemical Engineering Journal, 166, 616-623.

8. Kim, C., Bao, L., Okuyama, K., Shimada, M., \& Niinuma, H. (2006) Filtration efficiency of a fibrous filter for nanoparticles. Journal of Nanoparticle Research, 8: 215-221.

9. Kips, R., A. Leenaers, G. Tamborini, M. Betti, S. Van den Berghe, R. Wellum, and P. Taylor (2007) Characterization of uranium particles produced by hydrolysis of $\mathrm{UF}_{6}$ using SEM and SIMS, Microscopy and Microanalysis, 13: 156-164.

10. Miguel, A. F., Effect of air humidity on the evolution of permeability and performance of a fibrous filter during loading with hygroscopic and non-hygroscopic particles. Journal of Aerosol Science, 34: 783-799, 2003Pickrell, P.W. (1985) Characterization of the solid airborne materials created when $U F_{6}$ reacts with moist air flowing in single-pass mode, Martin Marietta Energy Systems, Inc. Report \# K/PS-1134, October.

11. Montgomery, J. F., Green, S. I., \& Rogak, S. N. (2015). Impact of relative humidity on HVAC filters loaded with hygroscopic and non-hygroscopic particles. Aerosol Science and Technology, 49, 322331.

12. Perry, J.L., J.H. Agui, and R. Vijayakumar (2016) Submicron and nanoparticulate matter removal by HEPA-rated media filters and packed beds of granular materials, NASA TM/2016-218224, May.

13. Pickrell, P.W. (1985) Characterization of the solid, airborne materials created when UF6 reacts with moist air flowing in single-pass mode, K/PS-1134, Report of Martin Marietta Energy Systems, Inc., Oak Ridge Gaseous Diffusion Plant, October.

14. Ribeyre, Q., Charvet, A., Vallières, C., \& Thomas, D. (2017). Impact of relative humidity on a nanostructured filter cake - experimental and modelling approaches. Chemical Engineering Science, 161, 109-116.

15. Saleem, M. \& G. Krammer (2007) Effect of filtration velocity and dust concentration on cake formation and filter operation in a pilot scaled jet-pulsed bag filter, Journal of Hazardous Materials, 144:677-681.

16. Thomas, D., P. Pénicot, P. Contal, D. Leclerc, \& J. Vendel (2001) Clogging of fibrous filters by solid aerosol particles experimental and modeling study, Chemical Engineering Science, 56:49-61. 